九州大学学術情報リポジトリ

Kyushu University Institutional Repository

Local People's Attitudes towards the Community Forestry : The Case Studies in the Central Dry Zone of Myanmar

Soe, Aung Kyaw

Professor, Laboratory of Forest Policy, Faculty of Agriculture, Kyushu University

Sato, Noriko

Professor, Laboratory of Forest Policy, Faculty of Agriculture, Kyushu University

https://doi.org/10.5109/22081

出版情報 : 九州大学大学院農学研究院紀要. 57 (1)，pp.273-280，2012-02. Faculty of Agriculture， Kyushu University

バージョン :

権利関係 : 


\title{
Local People's Attitudes towards the Community Forestry -The Case Studies in the Central Dry Zone of Myanmar-
}

\author{
Aung Kyaw SOE* and Noriko SATO ${ }^{1}$ \\ Laboratory of Forest Policy \\ Graduate School of Bioresource and Bioenvironmental Sciences, Faculty of Agriculture, \\ Kyushu University, Fukuoka 812-8581, Japan \\ (Received October 26, 2011 and accepted November 9, 2011)
}

\begin{abstract}
In Myanmar, the forests of the Local Supply Working Cycles (LSWC) are to be transformed into the Community Forests (CF). However, only 42,147 ha of the community forests could be established and put under the management of 572 Community Forestry Users Groups (CFUG) by the end of April 2010 and most were developed with the aids of the international organizations. Therefore, the community forestry development was still very limited in Myanmar. On the other hand, the CF program did not get full participation of all local residents. While some villagers of a community joined the CF program, some did not in some cases. In this study, it was investigated to know in what way the two groups of CF users and non-CF users were socio-economically different. In addition, the attitudes of non-CF users towards the CF program were also explored. The interview surveys using questionnaires were conducted in 2009 and 2010. The study found that CF users were socio-economically higher than non-CF users in general. Out of non$\mathrm{CF}$ users, the middle-classed villagers showed their interest in the program while the poor and the rich did not. To make the program a pro-poor, some additional incentives relevant to the poor such as Payment for the Environmental Service (PES) scheme should be added in the CF program.
\end{abstract}

Key words: Community Forestry, CF users, non-CF users, socio-economic status, attitudes, Myanmar

\section{INTRODUCTION}

By the late 1970s, the international conservations adopted various "conservation and development" approaches promoting the idea that conservation and development were interdependent (Fisher et al., 2000). Meanwhile the concept of social forestry had begun to gain prominence in international forestry dialogue and this governance reform is now broadly acknowledged as critical for combating deforestation (Scheyvens et al., 2007). In Myanmar, the Forest Law (1992) decentralizes the management and encourages people participation in forest management (FAO, 1997). The Forest Policy (1995) identifies people participation as an imperative (Ministry of Forestry, 1995). In consequence, the Community Forestry Instructions (CFI), that is a comprehensive and liberal legal framework to promote community participation in the forestry sector was issued by the Forest Department (FD) in 1995 (FAO, 1997). It clearly demonstrates the sharing of forest management responsibilities between the FD and the rural communities.

The basic premise of community forestry is that if the communities' knowledge about resource management is combined with more inclusive decision making processes, the result would be more equitable and more suitable natural resource management (Chevalier and Buckles, 1999) and the objective is to empower communities and resource users so that they develop and manage their resources (Means and Josayma 2002)

\footnotetext{
Professor, Laboratory of Forest Policy, Faculty of Agriculture, Kyushu University, Japan

* Corresponding author (E-mail: agkyawsoeone@gmail.com)
}

The forests of Local Supply Working Cycles (LSWC) are targeted to be transformed into the Community Forests (CF) in Myanmar (Ministry of Forestry, 2001). There are totally 7.071 million ha $(22.25 \%$ of the total forest land) of the forests in the LSWC (FAO, 2010). However, only 42,147 ha of the community forests (Table 1) could be established and put under the management of the respective local communities (572 CFUGs) by the end of April, 2010 (Planning and Statistics Division, FD, personal communication, Jan. 10, 2011). In fact, most of the initiatives had been conducted with the aids of the international organizations such as UNDP/FAO and JICA (Lin, 2005).

As to the participation of the local community in the CF program, it was not found that all villagers participated in the program in some cases. While some were participating in the program (CF Users), others of the same community were not yet (Non-CF Users). The study focused on this matter. It was investigated to know how different the two groups of CF user and non-CF users were socio-economically. In addition, the attitudes of non-CF users were also explored. In particular, it was investigated to know if they have any willingness to participate in the CF programs in the future.

\section{METHODOLOGY}

\section{Description of the Case Study Sites}

The case studies were conducted in two CF sites$\mathrm{CF}$ of natural forest conservation system (NFC-CF) and CF of agroforestry system (Agroforestry CF). Both sites are located in the Central Dry Zone of Myanmar where the severe drought is a significant feature of the region. The total area of the Dry Zone is over 6.7 million ha 
Table 1. Community Forestry Establishment (By the end of April, 2010)

\begin{tabular}{|c|c|c|c|c|c|c|c|c|}
\hline \multirow{2}{*}{ Sr. No. } & \multirow{2}{*}{ Regions } & \multicolumn{2}{|c|}{ RF/PPF (ha) } & \multicolumn{2}{|c|}{ UF (ha) } & \multirow{2}{*}{$\begin{array}{c}\text { Total } \\
\text { (ha) }\end{array}$} & \multirow{2}{*}{ CFUGs } & \multirow{2}{*}{$\begin{array}{c}\mathrm{CF} \\
\text { Users }\end{array}$} \\
\hline & & Plantation & NF & Plantation & NF & & & \\
\hline 1 & Kachin & 509.9 & 739.4 & & & 1249.3 & 3 & 348 \\
\hline 2 & Kayah & & & 40.5 & & 40.5 & 1 & 75 \\
\hline 3 & Kayin & & & & 446.4 & 446.4 & 4 & 278 \\
\hline 4 & Chin & & 232.7 & & 1014.0 & 1246.7 & 15 & 209 \\
\hline 5 & Sagaing & 16.2 & 149.7 & 865.1 & 693.6 & 1724.7 & 33 & 1434 \\
\hline 6 & Taninthari & & 99.1 & & 80.9 & 180.1 & 5 & 118 \\
\hline 7 & Bago (East) & 115.3 & & & & 115.3 & 4 & 116 \\
\hline 8 & Bago (West) & 120.4 & & & & 120.4 & 3 & 134 \\
\hline 9 & Mandalay & 3208.5 & 697.4 & 484.6 & 26.3 & 4416.8 & 99 & 2206 \\
\hline 10 & Magwe & 400.6 & 293.0 & 2969.4 & 593.2 & 4256.2 & 40 & 18188 \\
\hline 11 & Mon & 60.7 & 6.1 & & & 66.8 & 4 & 59 \\
\hline 12 & Rakhine & 4.0 & 314.8 & 399.4 & 632.4 & 1350.6 & 85 & 3447 \\
\hline 13 & Yangon & 301.5 & 8.1 & & & 309.6 & 6 & 210 \\
\hline 14 & Shan (South) & 4.5 & 9708.2 & & 11572.6 & 21285.3 & 192 & 10182 \\
\hline 15 & Shan (North) & 285.3 & 159.4 & 33.6 & 80.9 & 559.3 & 15 & 178 \\
\hline 16 & Shan (East) & & & & 2267.3 & 2267.3 & 14 & 652 \\
\hline 17 & Ayeyarwady & 1090.3 & 1421.1 & & & 2511.4 & 49 & 2228 \\
\hline Total (I & National) & 6117.3 & 13829.1 & 4792.6 & 17407.7 & 42146.6 & 572 & 40062 \\
\hline
\end{tabular}

RF/PPF: Reserved Forest/ Protected Public Forest (Management right to the Land belong to the FD)

UF: Unclassed Forest (Land at the disposal of the Government)

NF: Natural Forest

Source: Planning and Statistics Division, Forest Department (personal communication, Jan. 2011)

(9.2\% of the total land area of the country) and it has the population density of 171 per squared kilometer in 1993. The annual average rainfall of the entire region is $722.4 \mathrm{~mm}$ and there are about 50 raining days per year. The average highest and lowest temperatures of the region are $32.2^{\circ} \mathrm{C}$ and $10^{\circ} \mathrm{C}$, respectively. In this region, the deteriorations of the natural resources are very distinct and the socio-economic conditions of the residents are relatively lower (DZGD, 2000).

The NFC-CF site is located in Padauk-ngoke (new) village (20 17 ' 24.0" N; 95 17' 40.0” E), Natmauk Township, Magwe District. The village is 27 miles away from Magwe and located on the way to Natmauk from Magwe. At the time of survey (Dec, 2009), the village had 96 households and the population was 466. The major livelihood activities were farming and livestock breeding. The NFC-CF was established on the degraded forest located close to the village.

The Agroforestry CF site is located in Mezalican Village (20 48' 18.4” N; 96 10' 36.9” E), Thazi Township, Meiktila District. The village is 22 miles away from the

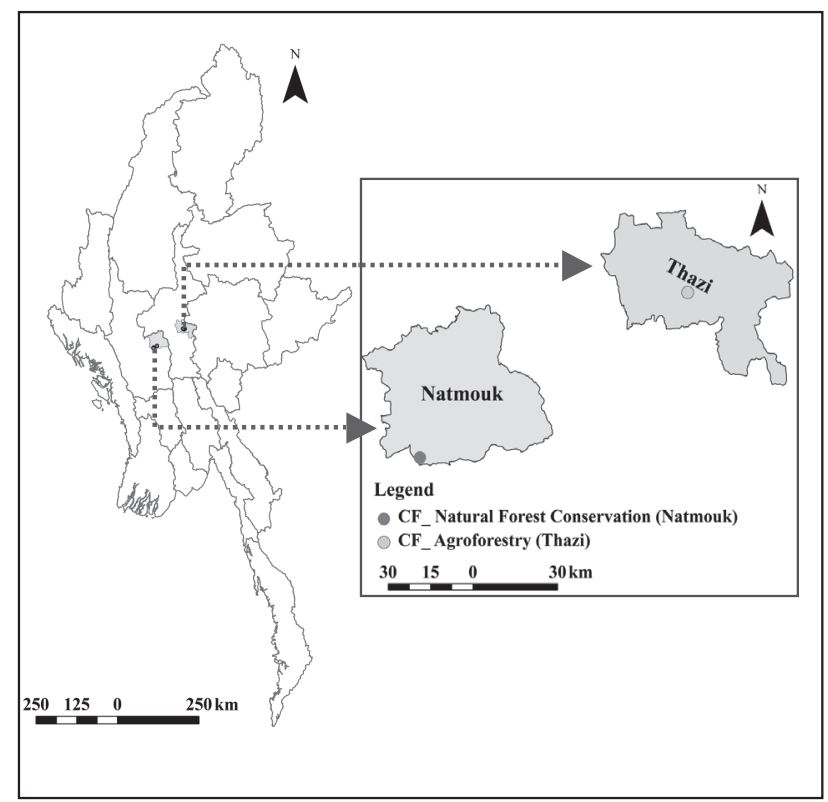

Fig. 1. Locations of the Case Study Sites.

Table 2. Case Study Sites, Locations and Dates of Survey

\begin{tabular}{ccccc}
\hline Sr. No. & Village & GPS Coordinates & Location & Survey Periods \\
\hline 1 & Padauk-ngoke & $20^{\circ} 17^{\prime} 24.0^{\prime \prime}$ N; $95^{\circ} 17^{\prime} 40.0^{\prime \prime} \mathrm{E}$ & Natmauk Township, Magwe District & Dec. 2009 \& Oct. 2010 \\
2 & Mezalican & $20^{\circ} 48^{\prime} 18.4^{\prime \prime}$ N; $96^{\circ} 10^{\prime} 36.9^{\prime \prime} \mathrm{E}$ & Thazi Township, Metila District & Jan. 2009 \& Sep. 2010 \\
\hline
\end{tabular}


Meiktila and located on the way to Taungyi from Meiktila. There were 360 households and the population was 2,078 at the time of survey (Jan. 2010). The major livelihood activities were the traditional cottage industry of making earth pots, farming and livestock breeding. Not so far from the village, the reserved forest (Yu-partaung) is located but it is severely degraded and covered with thorny bushes. On that forest land, the Agroforestry CF is established.

\section{Data Collection and Sampling}

The first field survey was conducted in December 2009 and January 2010. However, the second time field survey was again done in September and October 2010 because it was necessary to clarify some findings and to collect some CF data and information for the study. Basically, the study focused on the two groups in each case study site: CF users ${ }^{1}$ and Non-CF users $^{2}$. In both cases, the two groups of CF users and non-CF users were comparatively studied to know how different in the socio-economic status between them. In addition, the attitudes of non-CF users were also explored.

In the NFC-CF site, all CF users available in the village at the time of survey were selected for the interview. Out of $32 \mathrm{CF}$ users, $28 \mathrm{CF}$ users were interviewed then because the remaining $4 \mathrm{CF}$ users were not in the village at the time of the field survey. From the remaining households, 30 households were randomly selected for the study. Therefore, 58 informants were selected for the interview in this study site.

In the Agroforestry $\mathrm{CF}$ site, there were only $3 \mathrm{CF}$ users in the CFUG and a group consisting of 10 applicants was still applying for the CF establishment. They ${ }^{3}$ all were treated as the same group in the analysis. They all were interviewed. From the remaining households, 30 households were randomly selected for the study. Therefore, there were 43 informants in this study site. Regarding the format of questionnaire for each interviewee, it consisted of two main portions- the first portion was composed of the questions from which the socio-economic status of the interviewee could be investigated. And the second questions were to explore his/ her attitudes to the CF program. Some information and data related to the CF program were also collected from the respective District and Township offices, and the Headquarter.

\section{RESULTS AND DISCUSSION}

The Community Forestry Site (Padauk-ngoke Village) of Natural Forest Conservation (NFC-CF)

Out of the 96 households in the village, 32 households were being involved in the program. At the beginning of the program, the CFUG consisted of 39 households. Some CF users, who could not contribute their efforts to the program were removed/ resigned from the CFUG. The Certificate for CF establishment was issued on Feb. 16, 2005 and the area is 52 ha. The project provided the CFUG with an income generating activity of breeding goats (22 no.) that was worth $\$ 500$ to support their CF implementation activities on July 8, 2005. Now, they converted the livestock breeding into the microfinance system. They sold out all the goats in 2008 and lent the money to the CF users equally at an interest rate of $5 \%$ per month. Now, the capital lent to each user is Kyat $^{4} 13,000$ and so the CFUG has a total capital of Kyat 416,000 (in October 2010). They collected the interest from each user every 3 or 4 months. Having such financial capital, the CFUG appointed a member as a forest guard to protect the forest with a pay of Kyat 10,000 per month since August 2009.

According to the management plan, the community forest was divided into 5 equal plots on the map and so each of which has an area of about 10.4 ha. They adopted a rotation period of 5 years accordingly. The natural regeneration and gap planting activities were to be conducted plot by plot each year. Therefore, the whole CF area would be worked over in 5 years. At the end of rotation period (2010), they would be able to harvest some trees that attained the prescribed girth limit from the plot where the natural regeneration and gap planting activities were firstly conducted. In the management plan, the exploitable girth at the breast height (gbh) was fixed at $2 \mathrm{ft}(60 \mathrm{~cm})$. However, there were not many trees that had attained the prescribed gbh limit within the area in time for harvesting. Therefore, the CF users said they would continue the conservation activities.

Table 3. Number of Informants in Each Focused Group of the Study Sites

\begin{tabular}{ccccc}
\hline Sr. No. & Village & CF Users/ Applicants & Non-CF Users & Total \\
\hline 1 & Padauk-ngoke & 28 & 30 & 58 \\
2 & Mezalican & 13 & 30 & 43 \\
\hline \multicolumn{2}{r}{ Total } & 41 & 60 & 101 \\
\hline
\end{tabular}

\footnotetext{
${ }^{1}$ The villagers who are members of the community forestry users group (CFUG) (or) are involved in the group on the application process.

2 The villagers who did not join the CF program in any way.

${ }^{3}$ It represents both $\mathrm{CF}$ users and the applicants but the term "CF users" will be used in this article in general.

${ }^{4}$ Unit of Myanmar Currency (US $\$ 1=$ Kyat 828).

Source: The Myanmar Post Journal 3 (39), Oct 12, 2011
} 
Benefits and Effectiveness in Forest Conservation under the CF program

The CF users had got some small amount of firewood (about $360 \mathrm{ft}^{3}$ per user per year) that is a by-product of the natural regeneration activities conducted according to their management plan. Almost all respondents also said that the improvement in the forest condition was very significant and in consequence, they could collect nonwood forest products such as mushroom, fodder and roofing thatch from the community forest much more than others existing close to the CF. The provision of users' right to the group, not to each user individually, was found the main factor contributing to the effectiveness in the forest conservation.

Under the CF program, no individual member could cut the trees on his/her own intention/ requirement as on being the fact that the users' right belonged to the CFUG, not to any individual. In addition, the CFUG has a legal backing in protecting the forest and the forest guard appointed by the CFUG enforces the conservation activity. In case some illegal cutting occurred in the CF, the offender was fined for the disturbance by the chairman of the CFUG. It reveals that the local residents respect their legal right to the forest. Therefore, the forest was secure under the control of the CFUG and it resulted in such significant improvement in forest condition.

Comparison of the Socio-economic Statuses of CF Users and Non-CF Users

In general, the family sizes of CF users (average no. was 5.8) were larger than those of non-CF users (average no. was 4.6). The male population is also significantly higher in the group of the CF users (average no. was 3 in CF users and 1.8 in non-CF users). The statis- tics on the family members by age group was also comparatively investigated. In the age group (15 60 years), CF users had an average family members of 3.9 while non-CF users had 2.9. Regarding the sex ratio of household heads in each group, the proportion of female household heads was found very limited in the group of CF users (11\%) while it was relatively high in the group of non-CF users (33\%). The average age of the household heads accounted for 52.1 years in the group of CF users and 46.5 years in the group of non-CF users.

The education statuses of the household heads were not so different between the two groups. $89 \%$ of $\mathrm{CF}$ users and $90 \%$ of non-CF users belonged to the category of primary education level and the remaining proportions belong to the middle education level. In the categories of high school, university and graduate levels, the proportions of the family members of CF users were $7.4 \%, 1.9 \%$, and $0.6 \%$, respectively while those of the non-CF users were 3.6, 0.7, and 0.0. Therefore, in these mentioned categories, the proportions of CF users' family members were found relatively higher. Revealing that the education status of the family members of $\mathrm{CF}$ users could be said to be higher than that of non-CF users.

When the interview survey was conducted to each respondent, the general economic status (Good, Fair or Poor) was also investigated. The proportions belonging to the category of the poor were found very different between the two groups of CF users (4\%) and non-CF users (20\%). In addition, the average farm land area belonged to each CF user was again larger (3.24 acres vs 1.54 acres).

For the comparative study on annual income distributions of the two groups, a line representing a nationally adopted average annual expenditure (Kyat 1,165,000) ${ }^{5}$

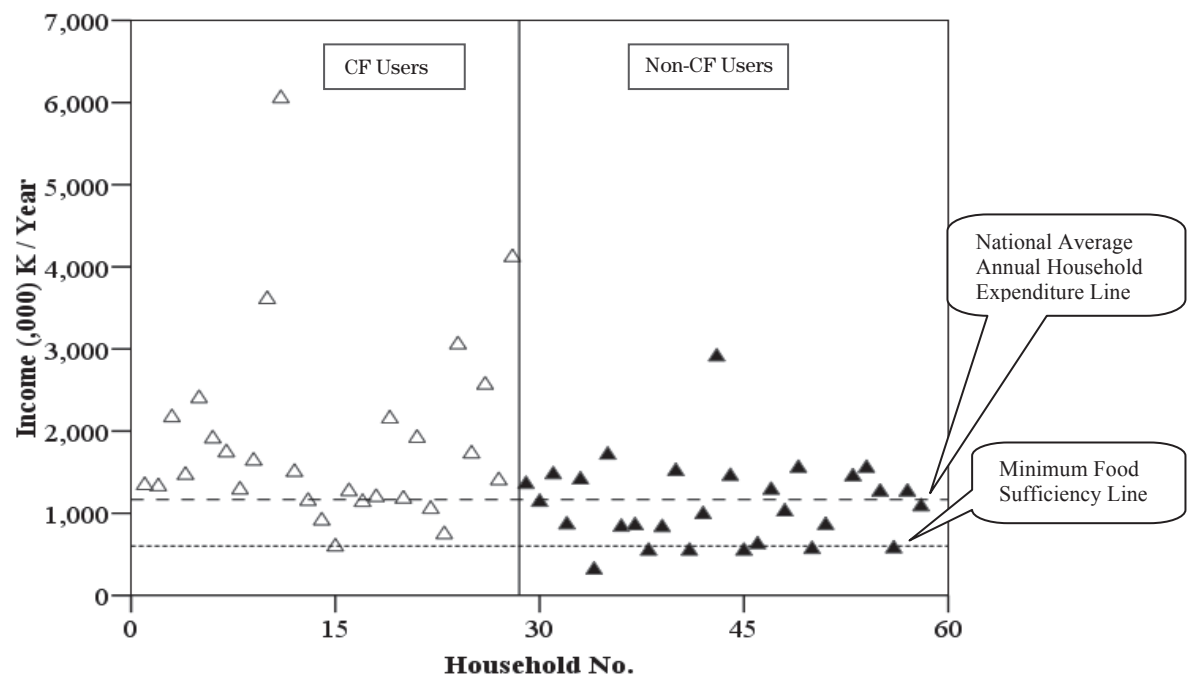

Fig. 2. Comparison of Annual Income Distributions between CF Users and Non-CF Users (NFC-CF).

\footnotetext{
5 Approximately equal to US\$ 1407

${ }^{6}$ Approximately equal to US\$ 725

(US $\$ 1$ = Kyat 828).

Source: The Myanmar Post Journal 3 (39), Oct 12, 2011
} 
of a household (CSO, 2008) and a line of minimum food sufficiency (Kyat $600,000^{6}$ per household per year) that was obtained from the discussion with a local resident were fixed to the figure of income distributions (Fig. 2) so that the significant difference could be seen. By the two lines, each group could be categorized into 3 subgroups: the better off who were located above the line of national average annual expenditure of a household; the fair who were located between the two lines and the poor who were located under the line of food sufficiency.

As to the Fig. 2, the proportion of CF users was significantly higher in the category of the better off $(78.5 \%$ Vs 46.7\%) while, conversely, their proportion was much lower in the category of the poor (3.6\% Vs 20\%). The difference was not so significant in the economically fair category (25\% of CF user Vs 33.3\% of non-CF users).

\section{Attitudes of Non-CF Users towards the CF Program}

For the investigation of attitudes of non-CF users towards the program, a question of "Do you want to be involved in the CF program if it is initiated in your village in future?" had been raised. The responses are as shown in the table (4).

Table 4. Attitudes of Non-CF Users towards the CF Program (NFC-CF)

\begin{tabular}{cccc}
\hline Sr. & Responses & No. of Respondents & $(\%)$ \\
\hline 1 & Yes & 9 & 30 \\
2 & No & 16 & 53 \\
3 & Yes (with condition) & 5 & 17 \\
\hline \multicolumn{2}{c}{ Total } & 30 & 100 \\
\hline
\end{tabular}

It was found that only some small proportion (30\%) of non-CF users were interested in the program while $53 \%$ were not. It was also interesting to find the reasons why the majority of non-CF users were not interested. $33 \%$ said they were seasonal workers (generally the poor) who could not live in the village all around the year; $13 \%$ gave the reasons of lack of working force or being too old; and the remaining 7\% (generally the better off) replied that they could not pay attention to the program due to their own business. One of the possible reasons why a large proportion of the non-CF users showed no interest in the program was that the benefits that could be obtained from the CF program could not be expected to be reliable for their livelihood. Therefore, some additional incentives should be provided in the $\mathrm{CF}$ program so as to motivate the interest of the local communities in the CF program.

$17 \%$ of non-CF users gave a response of "Yes but with conditions". They replied that they would join the program if the forests over which they had customarily controlled are targeted for CF establishment (7\%), if the other family members of his/her household are interested in the program (7\%) and if they are in the village at the time of initiating $\mathrm{CF}$ to their village (3\%). In the study site, some villagers were holding the customary users' rights to some forests and hence, they were afraid of losing their rights to their respective forests in case of establishing $\mathrm{CF}$ on their forest land. Therefore, they responded to the question that they would join the program if the CF is established on their customarily controlled forests. The issue of customary forest users' rights should be taken into consideration under the CF program.

It was also learnt that some villagers could not live in the village all around the year because they seasonally had to work away from the village as laborers. They were not sure whether they would be in the village at the time of establishing $\mathrm{CF}$ in future and so they could not give a clear response to the question. In fact, most of them were the poor who did not have enough income sources in their village. This is also an issue to be considered whether we should try to get their participation in or exclude them from the CF program in the future.

\section{The Community Forestry Site (Mezalican Village) of Agroforestry (Agroforestry CF)}

The Certificate for CF establishment was issued on April 26, 2006. The total area of CF is 50 ha and only 3 households were being involved in the CF program. In fact, there were 6 households when they applied for the permission. However, the other 3 members did not join the program on the implementation stage. In this case, the land was allocated for each user and the implementation was being conducted individually, not by group. Therefore, it was rather like a private forestry even though it was developed under the CF program. According to their management plan, the implementation was to be accomplished in 5 years. The total area to be annually implemented by all the members was 10 ha.

Table 5. Land Allocation among CF Users (Agroforestry CF)

\begin{tabular}{ccc}
\hline CF Users & Land Allocation (ha) & \% of the Total \\
\hline User 1 & 4 & 8 \\
User 2 & 36.5 & 73 \\
User 3 & 9.5 & 19 \\
\hline Total & 50 & 100 \\
\hline
\end{tabular}

\section{Benefits and Implementation Status}

Having a shot term income particularly from the agricultural crop constituted in the agroforestry system, CF users could enjoy the benefits from the beginning year of the implementation. The average annual cost contributed to and net profit obtained from the program by each user were as described in the table (6). With respect to the implementation status, it was found, as to the site observation that the CF users could hardly fulfill the obligations of planting trees. They said a lot of trees planted in the rainy season could not pass the summer when the severe drought occurred and the free grazing was normally practiced. It was also learnt that there were some conflicts between the CF users and cattle (cows) owners. 
Table 6. Average Annual Cost and Benefit in the Agroforestry CF by Each User (2006 2009)

\begin{tabular}{cccc}
\hline CF Users & Cost $(, 000) \mathrm{K}$ & Benefit $(, 000) \mathrm{K}$ & Net Profit $(, 000) \mathrm{K}$ \\
\hline User-1 & 44.2 & 180 & 135.8 \\
User-2 & 177.7 & 720.9 & 543.2 \\
User-3 & 163.8 & 276.3 & 112.5 \\
\hline Total & 385.7 & 1177.2 & 791.5 \\
\hline
\end{tabular}

(US $\$ 1=$ Kyat 828).

Source: The Myanmar Post Journal 3 (39), Oct 12, 2011

Comparison of the Socio-economic statuses of $C F$ Users and Non-CF Users

Generally, the demographic statuses of the two groups were not so different each other. The average family members, family members in the age group (15 60 years) and male pollution of CF users were slightly higher than that of non-CF users. A significant finding was that all the household heads in the group of $\mathrm{CF}$ users were found to be male while, in the group of non-CF users, $23 \%$ was the female household heads. The average age of the household heads of CF users was 46.1 years old and that of non-CF users was 49.6. Therefore, $\mathrm{CF}$ users were comparatively younger than non-CF users.

Regarding the education status of the household heads of the two groups, $15 \%$ of the CF users were graduates or had university level education while there was no one who had such education level in the group of non-CF users. In addition, the largest proportion (47\%) of the household heads of $\mathrm{CF}$ users belonged to the category of middle school level education while that (64\%) of non-CF users belonged to the category of primary level education. Therefore, the education statuses of CF users were significantly higher than those of non-CF users.
The student proportion of the family members of $\mathrm{CF}$ users $(32.4 \%)$ was very significantly higher than that of non-CF users (15.4\%). With respect to the education levels of the family members, the proportions belonging to the middle school, high school and university level education were $33.8 \%, 10.8 \%$ and $6.8 \%$, respectively in CF users' households while $25 \%, 4.5 \%$ and $1.3 \%$ in the group of the non-CF users. Therefore, the education statuses of the family members of $\mathrm{CF}$ users were again significantly higher in the mentioned levels. The proportions of graduates of the two groups were not so different: $(4.1 \%$ in the group of $\mathrm{CF}$ users and $4.5 \%$ in the group of non-CF users).

On the assessment of general economic status (Good, Fair or Poor), there was no one who fell into the category of the poor in the group of CF users while 10\% of non-CF users were the poor. However, the proportion of non-CF users (27\%) belonging to the category of the better off was slightly higher than that of CF users (23\%). In the economically fair category, there were $77 \%$ of $\mathrm{CF}$ users and $63 \%$ of non-CF users.

With respect to the farm land ownership, the average farm land area owned by CF users was found to be $1.8 \mathrm{ha}$ and that owned by non-CF users was $0.83 \mathrm{ha}$. Therefore, CF users' were higher than non-CF users' in the comparison of the farm land ownership. In the

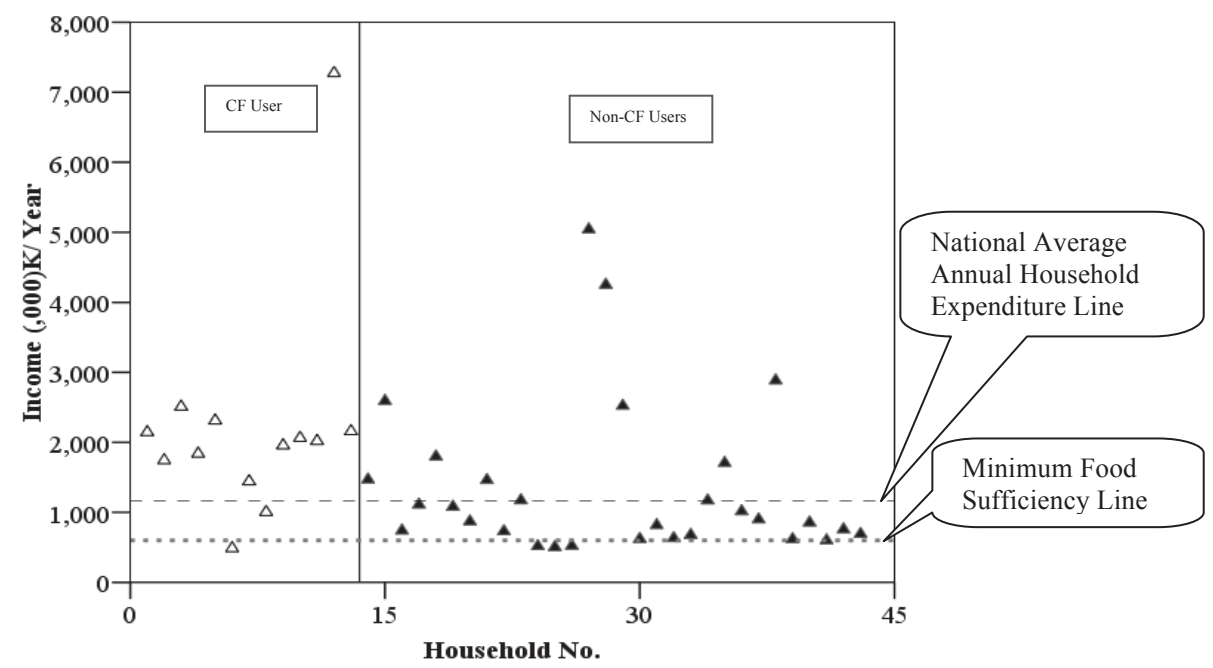

Fig. 3. Comparison on the Annual Income Distributions between CF Users and Non-CF Users (Agroforestry CF).

\footnotetext{
${ }^{7}$ It represents $3 \mathrm{CF}$ users and 10 applicants, who are the members of a group on the application process.
} 
annual income distributions comparison (Fig. 3), the proportion of $\mathrm{CF}$ users was significantly higher in the category of the better off (84.6\% Vs 36.6\%) while the large proportion of non-CF users was concentrated in the economically fair group (53.3\%).

\section{Attitudes of Non-CF Users towards the CF Program}

Here again, the question "Do you want to be involved in the CF program if it is initiated in your village?" had been raised. The results of responses are shown in the table (7).

Table 7. Attitudes of Non-CF Users towards CF Program (Agroforestry $\mathrm{CF}$ )

\begin{tabular}{cccc}
\hline Sr. & Responses & No. of Respondents & $\%$ \\
\hline 1 & Yes & 14 & 47 \\
2 & No & 10 & 33 \\
3 & Yes (with no capability) & 6 & 20 \\
\hline \multicolumn{2}{c}{ Total } & 30 & 100 \\
\hline
\end{tabular}

Relatively large proportion of non-CF users (47\%) showed their interest even though some respondents (33.3\%) were not interested in the program. Out of the respondents with a response of "Yes but with no capability" (20\%), 13.3\% of the respondents to whom the poverty made them incapable to be involved in the program could be expected to join the CF program if some financial support is provided. This finding showed that the Agroforestry CF has relatively high potential to develop in the future if it is strategically launched in such degraded forest lands with some initial financial support. Under the Agroforestry CF, the short termed benefits from the agricultural crop were found reliable for the livelihood of CF users and hence that income opportunity had been a big incentive to the local people.

However, there were some respondents (33\%), who had no willingness to participate in the program. Out of them, $17 \%$ (generally the better off) responded that they had their own businesses or sufficient income sources and so they were not interested in the program. 3.3\% of the respondents said that they would not join the program even if they have got the opportunity to join the program because they were not familiar with the farming practice. The remaining $13.3 \%$ replied that they would not be able to participate in the program because they were too poor to be involved in the program.

Therefore, there was totally $26.6 \%$ of the respondents for whom the poverty was the main limitation to their interest in the program. Without external financial support, the program seemed to be out of reach of the local poor. In fact, the program has a high potential to alleviate the poverty and so the program could be strategically deployed to meet the objectives of recovering the degraded forests and poverty alleviation at the same time.

\section{CONCLUSION AND RECOMMENDATIONS}

The study investigated the effectiveness of the CF program in the forest conservation and benefits to the respective local communities brought by the CF program. In addition, the differences in the socio-economic status between $\mathrm{CF}$ users and non-CF users, and the attitudes of non-CF users to the CF program were also explored.

In both cases of the NFC-CF and the Agroforestry $\mathrm{CF}$, CF users were generally higher in the socio-economic status. The results of investigating the attitudes of non-CF users revealed that, in general, the local people who belonged to the poor or wealthy groups were not interested in the program and they accounted for relatively large proportion of non-CF users in both cases. The middle-classed villagers were found to be high potential local people who could enter the CF program in future.

Specifically, the improvement in the forest condition revealed how the CF program could bring the very positive impact to the forest conservation in NFC-CF. For conserving the remaining degraded forests of the Central Dry Zone, this model was found very relevant to be adopted and hence it should be widely replicated there. However, it should have more incentives relevant to the needs of the local people because lack of the interest of a relatively large proportion of non-CF users in the model could be translated that the model did not have sufficient incentives to them. In fact, the CF program is also related to the rural development and hence it must embrace the needs and aspirations felt at the community level (FAO, 1978). Nowadays, the Payment for Environmental Service (PES) scheme is seen to be an effective tool in the forest conservation and, if it is attached to the CF program, it would bring a big incentive to the local communities. Where poverty is associated with environmental degradation, paying poor producers is likely to generate a "win-win" outcome, with both poverty reduction and environmental benefits obtained (FAO, 2007).

In the Agroforestry CF, the presence of short-termed income was significant and hence this practice could satisfy the urgent needs of the local people. Therefore, the Agroforestry CF system should be strategically deployed to alleviate the poverty. Regarding the attitudes of nonCF users, a relatively large proportion showed their interest in the CF program and so this system had a good potential to develop. However, there were also some villagers who responded that they had no willingness/ no capability to be involved in the CF program because of poverty. For them, the initial financial support was inevitably needed so that they could join the program. If not so, they would not be able to access to the CF program. If some kinds of microfinance system were attached to the CF program, this model could be deployed as an effective tool in the poverty reduction scheme that the government was enthusiastically launching in Myanmar. 


\section{ACKNOWLEDGEMENTS}

We gratefully acknowledge the 'Interdisciplinary Programs in Education and Projects in Research Development (P\&P Program)' of Kyushu University that provided us with the financial support for field survey. Dr. Sukeharu TSURU shared a lot of comments and suggestions with which we could clarify our findings during the research period. We thank him in deep.

\section{REFERENCES}

Chevalier, M. J. and D. Buckles 1999 Conflict Management: A Heterocultural Perspective. In Cultivating Peace: Conflict and Collaboration in Natural Resource Management. Daniel Buckles, ed. Ottawa: International Development Research Centre/ World Bank

CSO (Central Stestical Organization) 2008 Stestical Year Book (2008). Ministry of National Planning and Economic Development, Myanmar

DZGD (Dry Zone Greening Department) $2000 \quad$ The Integrated Master Plan for Greening the Dry Zone (2001-02 to 2030-31). Dry Zone Greening Department, Ministry of Forestry, the Union of Myanmar

FAO 1978 Forestry for Local Community Development. Forestry Paper 7. Rome
FAO 1997 Country Report-Union of Myanmar by the Forest Department, Ministry of Forestry, Myanmar. Asia-Pacific Forestry Outlook Study Working Paper Series. Working Paper No: APFSOS/WP/08. Rome: FAO

FAO 2007 The State of Food and Agriculture: Paying Farmers for Environmental Services. Rome, FAO

FAO 2010 Global Forest Resources Assessments 2010, Country Report: Myanmar. Rome: FAO

Fisher, R. J., P. B. Durst, T. Enters and M. Victor 2000 Overview of Themes and Issues in Devolution and Decentralization of Forest Management in Asia and the Pacific. In Decentralization and Devolution of Forest Management in Asia and the Pacific. Enter, T., Durst, P. B. and Victor, M. (eds). RECOFTC Report No.18 and RAP Publication 2000/1. Bangkok, Thailand

Lin, H. 2005 Community Forestry Initiatives in Myanmar: An Analysis from a Social Perspective. International Forestry Review, $\mathbf{7}(1)$ : 27-36

Means, K. and C. Josayma 2002 Community-Based Forest Resource Conflict Management. Rome: FAO

Ministry of Forestry 1995 Forest Policy, 1995. Yangon, the Union of Myanmar

Ministry of Forestry 2001 National Forestry Master Plan (20012002 to 2030-2031) Ministry of Forestry, the Union of Myanmar

Scheyvens, H., K. Hyakumura and Y. Seki (eds.) 2007 Forest Governance in a State of Transition. In Decentralization and state-sponsored community forestry in Asia. Institute for Global Environmental Strategies, Japan 